\title{
Plant roles and decision autonomy in multinational plant networks
}

\author{
Catherine A. Maritan ${ }^{\mathrm{a}, *}$, Thomas H. Brush ${ }^{\mathrm{b}}$, Aneel G. Karnani ${ }^{\mathrm{c}}$ \\ a Jacobs Management Center, School of Management, State University of New York at Buffalo, Buffalo, NY 14260, USA \\ ${ }^{\mathrm{b}}$ Krannert School of Management, Purdue University, 403 West State Street, West Lafayette, IN 47907, USA \\ c University of Michigan Business School, 701 Tappan St., Ann Arbor, MI 48109, USA
}

Received 25 July 2002; received in revised form 17 May 2004; accepted 27 May 2004

Available online 20 July 2004

\begin{abstract}
The paper examines whether plants in a multinational manufacturing firm with different roles have different degrees of autonomy concerning planning, production and control decisions. Building on Ferdows' framework for classifying international plants in a network, we empirically examine the proposition that the degree of managerial autonomy varies according to strategic role of the plant. We ask whether different plant roles require different management systems and different levels of responsibility for decisions and find evidence of differentiated fit.
\end{abstract}

(C) 2004 Elsevier B.V. All rights reserved.

Keywords: Operations strategy; Global operations

\section{Introduction}

A company can manage a group of plants as a multinational network to learn more about technology, customers, products or processes than it would learn in one location (MacCormack et al., 1994). It may also gain advantages in cost or flexibility from managing a group of plants as a network that it would not achieve if these plants were managed as stand alone entities (Scherer et al., 1975). One advantage of optimizing a system of plants is that individual plants can specialize in activities. To derive the benefits of specialization, plants must be managed to integrate material flows, management skills, product/process developments, or

\footnotetext{
* Corresponding author. Tel.: +1-716-645-3245; fax: +1-716-645-6117.

E-mail address: cmaritan@buffalo.edu (C.A. Maritan).
}

other knowledge among plants. Plants develop roles and have distinct management systems in place to then transfer the benefits of the specialization back to the other plants in the network. Accordingly, there should be a fit between the way a plant is managed and what is necessary to provide the integration for its particular specialized plant role. An important management characteristic that may differ among plants in such a network is the degree of autonomy the plant management has concerning different types of decisions about the planning, production, and control of the plant. This paper uses a survey of international plant managers to investigate whether there is a fit between the degree of autonomy over these key decisions and the role of a plant in a network.

There are many conceptual articles that address the challenges of coordinating a multiplant network in an international context (Ferdows, 1989, 1997; Flaherty, 
1986; Oliff et al., 1989). Some of these frameworks are derived for the entire network in terms of material flows (Flaherty, 1986), or for a plant type which characterizes the network (Schmenner, 1982). Another approach describes the role of the plants relative to a network and allows for different plant roles within the same network (Ferdows, 1989, 1997). We build on this approach as developed by Ferdows because of its implications for managing different plant roles within a network. While Ferdows focuses on what the appropriate role for a plant would be in different circumstances, and others focus on how plant roles may change over time (e.g., Khurana and Talbot, 1998), we focus on how to manage a plant given a particular role.

We are particularly interested in the degree of autonomy a plant has over key decisions because this is a critical dimension representing differences in management authority. Centralization is a key dimension of organization structure that concerns the locus of authority to make decisions (Pugh et al., 1968). A plant operating in a business unit with a high degree of centralization would have a low degree of autonomy, with most of the important decisions being made at a higher level in the organization such as business unit headquarters or the corporate office. Conversely, a plant with a high degree of autonomy would control many of its important decisions. We expect that plants with different roles should have different degrees of autonomy. If managers use similar systems throughout the business unit to manage plants with different strategic roles, the systems may be compromised for all plants, or some plants may be managed inappropriately. On the other hand, if managers know which management systems need to be linked to specific plant roles, they can differentiate the management systems within their network to match the roles of plants. We use the empirical findings of our study to identify the specific differences in management systems that occur when different plant types operate within the same network.

The following section positions the Ferdows framework relative to other research on multinational firms which emphasizes fit, and puts our empirical study on the management implications of multinational plant networks in that context. This is followed by a description of the research design and development of our hypotheses. We then report the empirical tests and our findings. We conclude with a discussion of key results and the implication of our findings.

\section{Theoretical background}

In relationships between corporate headquarters and country subsidiaries in multinational firms (e.g., Prahalad and Doz, 1987; Bartlett and Ghoshal, 1989; Nohria and Ghoshal, 1994), and between corporate headquarters and the strategic business units in diversified firms (Gupta and Govindarajan, 1986, 1991), it is important to consider the "fit" between the context of the subsidiary or the business unit and the systems used to manage them. Different strategic roles of subsidiaries or business units may require different management systems. A similar logic can be applied to the relationship between a business unit headquarters and individual plants in a multiplant network. We draw on this logic to investigate the fit between the context of the plant, which we define as the plant role, and the way in which the plant should be managed (Venkatraman, 1989; Dean and Snell, 1991). While there are conceptual articles arguing for the importance of considering a plant level manufacturing strategy (e.g., Skinner, 1974), empirical work has generally not conditioned the manufacturing strategy of the plant by its position in a network of plants. Empirical studies of taxonomies of manufacturing strategies are primarily interested in the fit of business unit competitive strategy with plant characteristics (Kotha and Vadlamani, 1995; Miller and Roth, 1994; Roth and Miller, 1992; Swamidass and Newell, 1987). In contrast, we are concerned with the fit of a plant level manufacturing role with the differentiation of management systems' relative autonomy among plants within a business unit.

We build our analysis on the plant roles defined by Ferdows $(1989,1997)$ (refer to Fig. 1). He developed a framework that defines six plant roles based on two dimensions: (1) the primary reason for establishing the factory and (2) the extent of technical activities at the site. Primary reason for the site is divided into three categories: (1) access to low cost production input factors, (2) use of local technological resources and (3) proximity to market. Extent of technical activities is classified as being either low or high. Plants having a low level of technical activities at the site are labeled Off-Shore, Outpost, or Server depending on whether they are located for access to inputs, local technology or markets, respectively. Plants having a high level of technical activities are labeled Source, Lead, or Con- 
Generic Roles of International Factories

(Ferdows, 1989)

Primary Strategic Reason for the Site

\begin{tabular}{|l|c|c|c|c|}
\hline \multicolumn{2}{|l|}{} & $\begin{array}{c}\text { Access to Low Cost } \\
\text { Production Input } \\
\text { Factors }\end{array}$ & $\begin{array}{c}\text { Use of Local } \\
\text { Technological } \\
\text { Resources }\end{array}$ & $\begin{array}{c}\text { Proximity } \\
\text { to Market }\end{array}$ \\
\hline \multirow{2}{*}{$\begin{array}{l}\text { Extent of } \\
\text { Technical } \\
\text { Activities at Site }\end{array}$} & High & Source & Lead & Contributor \\
& Low & Off-Shore & $n=37$ & $\mathrm{n}=40$ \\
& & $\mathrm{n}=35$ & Outpost & Server \\
& & & $\mathrm{n}=22$ & $\mathrm{n}=43$ \\
\hline
\end{tabular}

Fig. 1. Generic roles of international factories (Ferdows, 1989).

tributor when located for inputs, local technology, or markets, respectively. Because our analysis is based on this framework, we describe Ferdows' plant types here in some detail.

\subsection{Plants located close to low cost production inputs}

An Off-Shore plant is located to take advantage of low cost production inputs. The products or components that are manufactured are typically shipped to other facilities in the business unit. Only the minimum technical and managerial expertise required for production is maintained. In these plants there is no real engineering work, procurement decisions are very short-term oriented, accounting and finance are strictly for reporting to the home country management, and the pattern of shipments are simple and not in the control of the Off-Shore plant management.

A Source plant is also located to take advantage of low cost production inputs. But, unlike an Off-Shore plant, there is both technical and managerial expertise at the site because Source plants tend to specialize in producing particular components or products, or in using particular production processes on behalf of other facilities in the business unit.

\subsection{Plants located for proximity to market}

A Server plant is located to manufacture a product for a local market. Although there is a relatively low level of technical and managerial expertise at the site, there is some managerial autonomy over material and information flow so that the plant can be responsive to local market needs.

A Contributor plant is also located to serve a local market. But, unlike a Server, it has a higher degree of managerial and technical expertise at the site to develop and transfer know-how to other facilities in the business unit. Like Source plants, Contributors specialize not only for themselves, but also on behalf of the other facilities.

\subsection{Plants located for use of local technological resources}

An Outpost plant is located for access to local technology and is established to collect information from customers, suppliers, and competitors on behalf of the business unit. The Outpost plant does not have the managerial depth to act on this information but will pass it on to other plants to do so.

Finally, a Lead plant is also located for access to local technology. But, in addition to collecting technological information for its business unit, it uses the information to innovate and develop manufacturing capabilities. The products and processes it develops may be transferred to other facilities in the business unit. To support this role, a high level of managerial and technical expertise is required at the site. 
Through these descriptions, Ferdows (1989) defines generic plant types and outlines broad strategic roles for these different types. Within the broad confines of these roles we focus on autonomy over key decisions and develop hypotheses for how autonomy over decisions will differ by plant type.

\section{Research design}

\subsection{Classification of plants}

The data used in this analysis are from the Global Manufacturing Network Survey conducted at the Graduate School of Business Administration at the University of Michigan. The purpose of this survey was to assemble a comprehensive database containing a variety of data regarding the configuration and operation of multinational manufacturing plant networks. The survey was administered to plant managers in 31 countries whose corporate headquarters are located primarily in the US, Western Europe, and Japan. All participating firms had sent managers to the Global Leadership Executive Management Program at the University of Michigan, demonstrating an interest in and concern for education on management of international manufacturing enterprises. These managers took surveys back to their companies and distributed them to plant managers. The response rate was exceptionally high (above $90 \%$ ) for this reason.

From 209 survey responses, we identified 196 plants that are distributed into all six of the strategic role categories of Ferdows (1989): (i) Source (19), (ii) Off-Shore (35), (iii) Lead (37), (iv) Outpost (22), (v) Contributor (40) and (vi) Server (43). The remaining 13 observations were eliminated due to missing responses. Appendix A contains a profile of the sample plants. The plants are owned by 47 companies, are located in 30 countries and represent 41 industries (as defined by 3-digit SIC codes). Plants were classified into the six categories in terms of the primary strategic reason for the site and technical activities at the site (Ferdows, 1989). The survey items used to classify the plants by their roles are found in Table 1 . To facilitate analysis, each plant in the sample is assigned a single role. Although Ferdows acknowledges that some factories may combine two or more roles, he argues that "this simple framework is helpful in articulating the strategic contributions of most foreign factories" $(1997,77)$.

To determine the primary strategic reason for establishing the plant we used responses to the following question: "To what degree did the following factors influence your plant's location decision?" A set of location determinants was provided and respondents rated each on a 6-point scale where 0 is "not at all" and 5 is "very large extent". We grouped the location determinants that the respondents rated into the three strategic reasons for the site used by Ferdows. We considered access to raw materials, access to low-cost labor, access to energy and access to key suppliers to comprise the strategic reason, access to low cost production input factors. Access to local technology, access to skilled labor and access to advanced infrastructure comprise the second strategic reason, use of local technological resources. Finally, proximity to important markets and proximity to market comprise the third strategic reason, proximity to market. To determine the primary strategic reason for locating each plant we selected the location determinant that rated the highest score. Ties were settled by comparing the average score for the items in each group.

To determine the technical activities at the site we used responses to the question: "Who has the primary

Table 1

Items used to identify plant roles

\begin{tabular}{|c|c|c|c|}
\hline \multirow{2}{*}{$\begin{array}{l}\text { Extent of technical } \\
\text { activities at the site }\end{array}$} & \multicolumn{3}{|c|}{ Primary strategic reason for the site } \\
\hline & $\begin{array}{l}\text { Access to low cost production } \\
\text { input factors }\end{array}$ & $\begin{array}{l}\text { Use of local technological } \\
\text { resources }\end{array}$ & Proximity to market \\
\hline Responsibility for & Access to & Access to & Proximity to \\
\hline Original product design & Low cost labor & Local technology & Important markets \\
\hline Original process design & Raw materials & Skilled labor & Key customers \\
\hline Changes in product design & Energy & Advanced infrastructure & \\
\hline Changes in process Design & Key suppliers & & \\
\hline
\end{tabular}


responsibility for the following tasks for your plant?" The following tasks were considered: original product design, product design changes, original process design and process design changes. All of these tasks require technological competence to perform and we assume that autonomy over these tasks means that the plant possesses the requisite competence to effectively complete them. Respondents rated the items using a 5 -point scale where 1 is "worldwide headquarters", 2 is "regional headquarters", 3 is "another plant", 4 is "your plant in coordination with another plant" and 5 is "your plant". Only responses of "your plant in coordination with another plant" or "your plant" indicate that these technical activities take place at the site so if a respondent answered either 4 or 5 , the plant was assigned a score of 1 for that item, otherwise it was assigned as 0 . The scores for the four items were summed and each plant had an overall score of $0-4$ for its technological competence rating. An overall rating of 0 or 1 means that the plant performs no more than one of product design, product design changes, process design or process design changes. We considered this to constitute a relatively low level of technical ac- tivities at the site. We considered a rating of 2-4 to represent a relatively high level of technical activities at the site.

To assess the reasonableness of this cut-off we examined the average technological competence rating for the plants in each role. Although Ferdows defines only two categories in the framework, high and low, his descriptions of the plants indicate that there is more variation. Our Lead plants have the highest rating (3.32) followed by Contributor (2.88) and Source (2.32) plants. The relative ratings correspond to the descriptions giving us some confidence in our classification method.

\subsection{Factor analysis}

The explanatory variables in the model are measures of the degree of autonomy that the plant has over different categories of management decisions. We sought to understand whether particular decisions are controlled by the plant or by other parts of the network. For each type of decision listed in Table 2 respondents were asked "Who has the primary responsibility for the

Table 2

Decision autonomy means for plant roles (1-5 scale)

\begin{tabular}{|c|c|c|c|c|c|c|c|c|}
\hline Factors & Management decisions & $\begin{array}{l}\text { All plants } \\
(n=196)\end{array}$ & $\begin{array}{l}\text { Source } \\
(n=19)\end{array}$ & $\begin{array}{l}\text { Lead } \\
(n=37)\end{array}$ & $\begin{array}{l}\text { Contributor } \\
(n=40)\end{array}$ & $\begin{array}{l}\text { Off-Shore } \\
(n=35)\end{array}$ & $\begin{array}{l}\text { Outpost } \\
(n=22)\end{array}$ & $\begin{array}{l}\text { Server } \\
(n=43)\end{array}$ \\
\hline \multirow[t]{4}{*}{$\begin{array}{l}\text { Planning } \\
\text { decisions }\end{array}$} & $\begin{array}{l}\text { Long range production } \\
\text { planning }\end{array}$ & 3.30 & 3.79 & 3.49 & 3.33 & 2.94 & 2.68 & 3.49 \\
\hline & Production scheduling & 4.52 & 4.84 & 4.68 & 4.63 & 4.49 & 3.77 & 4.56 \\
\hline & Quality standards & 3.02 & 3.42 & 3.68 & 3.53 & 2.77 & 1.91 & 2.56 \\
\hline & $\begin{array}{l}\text { Maintenance policies and } \\
\text { practices }\end{array}$ & 4.58 & 4.53 & 4.59 & 4.88 & 4.34 & 4.77 & 4.42 \\
\hline \multirow{3}{*}{$\begin{array}{l}\text { Production } \\
\text { decisions }\end{array}$} & Raw material sourcing & 3.46 & 4.11 & 3.76 & 4.05 & 3.54 & 2.59 & 2.77 \\
\hline & Component sourcing & 3.83 & 4.26 & 3.89 & 4.30 & 4.09 & 2.82 & 3.47 \\
\hline & Equipment sourcing & 4.14 & 4.68 & 4.38 & 4.58 & 3.97 & 3.41 & 3.79 \\
\hline \multirow[t]{6}{*}{$\begin{array}{l}\text { Control } \\
\text { decisions }\end{array}$} & $\begin{array}{l}\text { Human resource policies } \\
\text { for management }\end{array}$ & 2.44 & 2.68 & 2.43 & 2.68 & 1.94 & 2.77 & 2.37 \\
\hline & $\begin{array}{l}\text { Human resource policies } \\
\text { for labor }\end{array}$ & 3.50 & 3.84 & 3.43 & 4.13 & 2.94 & 3.36 & 3.35 \\
\hline & $\begin{array}{l}\text { Choice of accounting } \\
\text { system }\end{array}$ & 2.20 & 2.95 & 2.22 & 2.58 & 1.83 & 1.73 & 2.05 \\
\hline & $\begin{array}{l}\text { Choice of management } \\
\text { information system }\end{array}$ & 2.69 & 2.63 & 2.81 & 3.18 & 2.46 & 2.50 & 2.44 \\
\hline & $\begin{array}{l}\text { Choice of production } \\
\text { planning and control } \\
\text { system }\end{array}$ & 3.31 & 3.37 & 3.54 & 3.80 & 2.74 & 3.23 & 3.14 \\
\hline & All decisions & 3.41 & 3.76 & 3.57 & 3.80 & 3.17 & 2.96 & 3.20 \\
\hline
\end{tabular}


following tasks for your plant?" using a 5-point scale in which "your plant" is 5, "your plant in coordination with another plant" is 4 , "another plant" is 3 , "regional headquarters" is 2 , "worldwide headquarters" is 1 .

The 12 decision types were factor analyzed to determine if it is appropriate to group them into categories. We used the principal components method with varimax rotation. The number of factors was determined using a scree plot. The resulting set of three management system factors and the items that loaded on each are listed in Table 2. The first factor captures Planning decisions and includes long range production planning, production scheduling, quality standards and maintenance policies and practices. The second factor captures Production decisions and includes raw ma-

Schematic Diagram for Hypotheses

Arrows Represent Pairwise Contrasts

Decisions

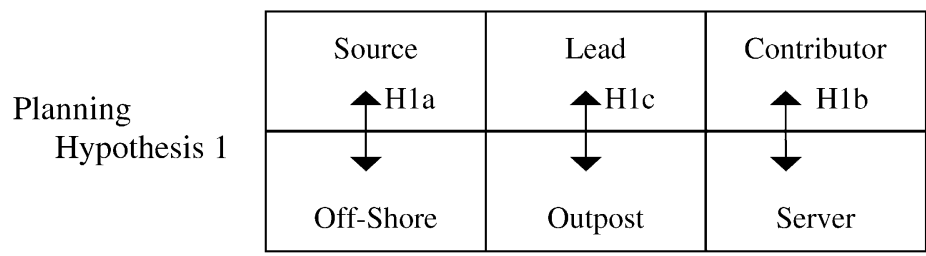

Planning

Hypothesis 2
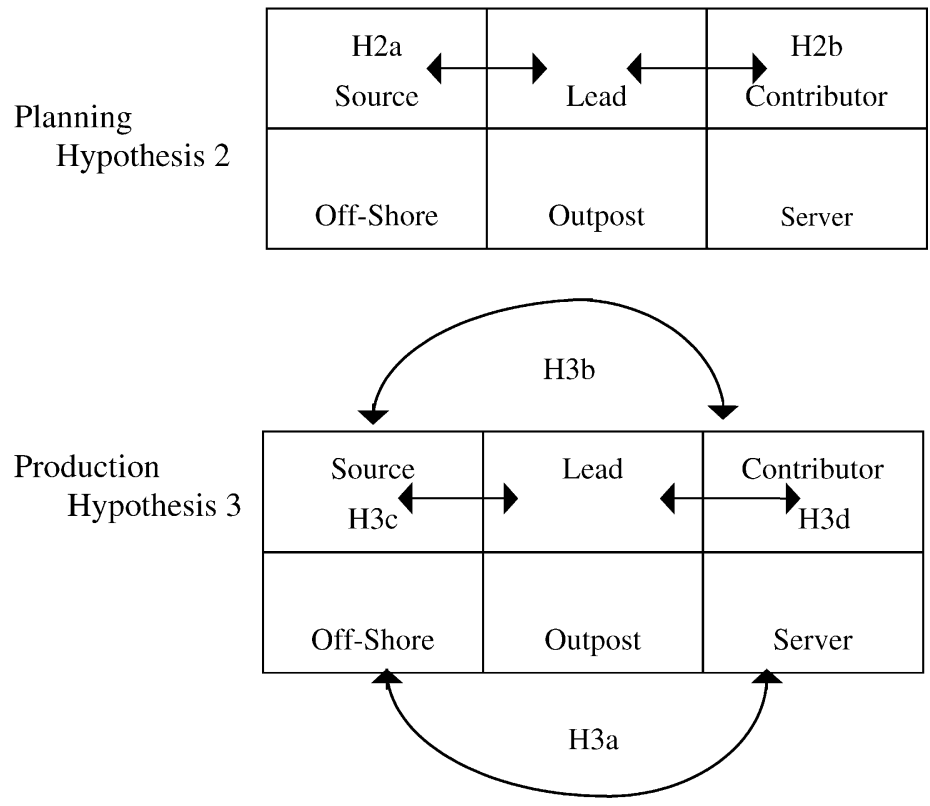

Control

Hypotheses 4

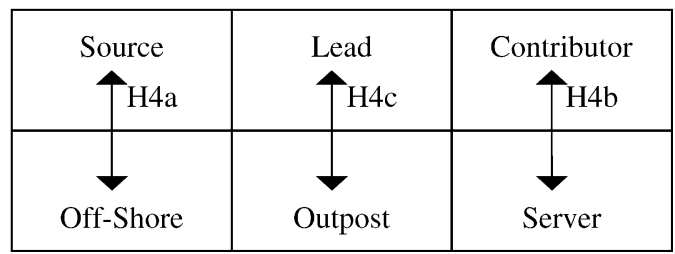

Fig. 2. Schematic diagram for hypotheses. Arrows represent pairwise contrasts. 
terial sourcing, component sourcing, and equipment sourcing. The third factor captures Control decisions and includes HR policies for management, HR policies for labor, choice of cost accounting system, choice of management information system and choice of production planning and control system.

\section{Hypotheses}

Do the fits that we observe between the plant roles and autonomy over key management decisions match those suggested by Ferdows? The following sections investigate this question. We develop hypotheses for pairwise contrasts in plant roles concerning different levels of autonomy for key management decisions. We do not develop hypotheses for all possible pairwise contrasts and all three decision types, planning, production and control. Instead, we focus on contrasts that appear to be most plausible and that are generally consistent with the Ferdows' descriptions. Because these issues of plant roles in multinational firms have not been explored empirically in a large sample context it is worthwhile to develop hypotheses for as many contrasts as we can, while still having a rationale consistent with the general differences between plant roles. In this way, we are both seeking to confirm some of the basic dimensions in the framework, as well as to surface some possible inconsistencies in the way autonomy for decisions may be understood relative to the framework. Fig. 2 summarizes the hypotheses.

\subsection{Autonomy over planning decisions}

A key element of Ferdow's framework is differences in technological competence. Plants within a single column of the framework are located for a similar reason but differ in terms of the technical activities at the site. Based on Ferdows' descriptions, plants with fewer technical activities at the site also have less management depth. In Off-Shore, Outpost and Server plants managerial investment is kept solely at the level needed for day-to-day management of the plant. So, we consider the degree of investment in management at the plant and ask if plants with more management depth have greater autonomy over planning decisions. Modifying key planning decisions might require the ability to make changes in processes or products at the plant. Thus autonomy for these decisions should be greatest in plants that have a higher level of technological competence at the plant site. Therefore, we expect Source, Contributor and Lead plants to enjoy more autonomy on these dimensions than Off-Shore, Server and Outpost plants respectively.

H1a. Source plants will differ from Off-Shore plants in their greater autonomy over planning decisions (such as long range production planning, production schedules, quality standards and maintenance policies and practices).

H1b. Contributor plants will differ from Server plants in their greater autonomy over planning decisions (such as long range production planning, production schedules, quality standards, and maintenance policies and practices).

H1c. Lead plants will differ from Outpost plants in their greater autonomy over planning decisions (such as long range production planning, production schedules, quality standards, and maintenance policies and practices).

Even within the plants that have a high extent of technical activities at the site there are differences in technological competence. Lead plants are located for access to technology. These factories may be the sole producer of key products or components for the business unit or may initiate new technologies that are not dependent on interactions with suppliers or customers. The Lead plant will have the most managerial autonomy on technical decisions that relate to the ability to develop and produce new products and processes. We expect Lead plants to have even greater control and autonomy with regard to planning decisions involving technical activities.

H2a. Lead plants will differ from Source plants in their greater autonomy on planning decisions (such as long range production planning, production schedules, quality standards, and maintenance policies and practices).

H2b. Lead plants will differ from Contributor plants in their greater autonomy on planning decisions (such 
as long range production planning, production schedules, quality standards, and maintenance policies and practices).

\subsection{Autonomy over production decisions}

Given a common level of technical activity at the plant site, what are the differences in autonomy over production decisions among plants that are located for access to markets versus those that are located for access to low cost inputs? The primary contrast between Off-Shore and Server plants and between Source and Contributor plants involves the management of material flows and selection of equipment and production processes that might be locally or regionally determined. Since the plants located for access to inputs must produce products that are fed into a system of inputs used by other plants, we would expect that they have less autonomy than plants that are serving markets. For the plants whose mission is related to markets, their processes need to be primarily suitable to their customers. To allow for this flexibility they should have more autonomy over key production decisions.

H3a. Server plants will differ from Off-Shore plants in their greater autonomy over production decisions (such as raw material sourcing, component sourcing and equipment sourcing).

H3b. Contributor plants will differ from Source plants in their greater autonomy over production decisions (such as raw material sourcing, component sourcing and equipment sourcing).

Lead plants have a higher level of technological competence at the site than Contributor and Source plants. Thus when it comes to production decisions, one might also expect Lead plants to have greater autonomy on key decisions related to production regarding important production sourcing decisions such as raw material sourcing, component sourcing and equipment sourcing than either Source or Contributor plants.

H3c. Lead plants will differ from Source plants in their greater autonomy over production decisions (such as raw material sourcing, component sourcing, and equipment sourcing).
H3d. Lead plants will differ from Contributor plants in their greater autonomy over production decisions (such as raw material sourcing, component sourcing, and equipment sourcing).

\subsection{Autonomy over control decisions}

Since there is greater management depth in the plants with more technological competence we also expect that they will have greater autonomy over control decisions that are concerned with management objectives across the network. Headquarters will in general retain authority over many control decisions and practices but we expect that plants with technical activities at the site will still have greater autonomy over these decisions than plants that do not.

H4a. Source plants will differ from Off-Shore plants in their greater autonomy over control decisions (such as human resource policies for management, human resource policies for labor, choice of cost accounting system, choice of management information system, and choice of production planning and control system).

H4b. Contributor plants will differ from Server plants in their greater autonomy over control decisions (such as human resource policies for management, human resource policies for labor, choice of cost accounting system, choice of management information system, and choice of production planning and control system).

H4c. Lead plants will differ from Outpost plants in their greater autonomy over control decisions (such as human resource policies for management, human resource policies for labor, choice of cost accounting system, choice of management information system, and choice of production planning and control system).

\section{Empirical test}

We tested the hypotheses using a multinomial logit model as a discriminant technique (Press and Wilson, 1978). The dependent variable in the analysis 
is categorical, representing a plant's role. The explanatory variables are the management system factors that indicate the plant's autonomy over planning, production and control decisions. A logit approach allows us to consider the decision factors as a system. Because a large proportion of plants are located in one country, the US, a 0-1 indicator variable was included to control for any resulting location effect. Stata 7.0 econometric software was used to estimate the model.

Table 2 reports mean levels of autonomy for different plant types and different decisions. Table 3 reports results of the logit model estimation. Results are reported as pairwise contrasts between plant types. A significant coefficient for a factor indicates that the factor significantly discriminates one plant type from the other.

\subsection{Descriptive characteristics of autonomy}

For plants that are part of a network, are there some decisions which headquarters wants to control regardless of the type of plant? Plants in this sample have the least autonomy (smallest numbers) over Control decisions such as human resource policies for management and choice of accounting system. This is not surprising given that standardization across plants in a network on these management systems could be important. Planning decisions such as production scheduling and maintenance policies and practices show very little indication of centralized decision making. The higher means for planning decisions indicate that these decisions are examples of systems that are inherently highly plant specific.

Taking an average across decision types for each plant type provides an indication of the overall autonomy of a plant. Contributor and Source plants have the most autonomy while Outpost plants have the least autonomy. Plants with a high extent of technical activities at the site (Source, Lead, Contributor) have more autonomy than those that do not (Off-Shore, Outpost, Server).

\subsection{Autonomy over planning decisions}

The finding that there are differences in autonomy over planning decisions for plants located for the same reason but with different levels of technol-

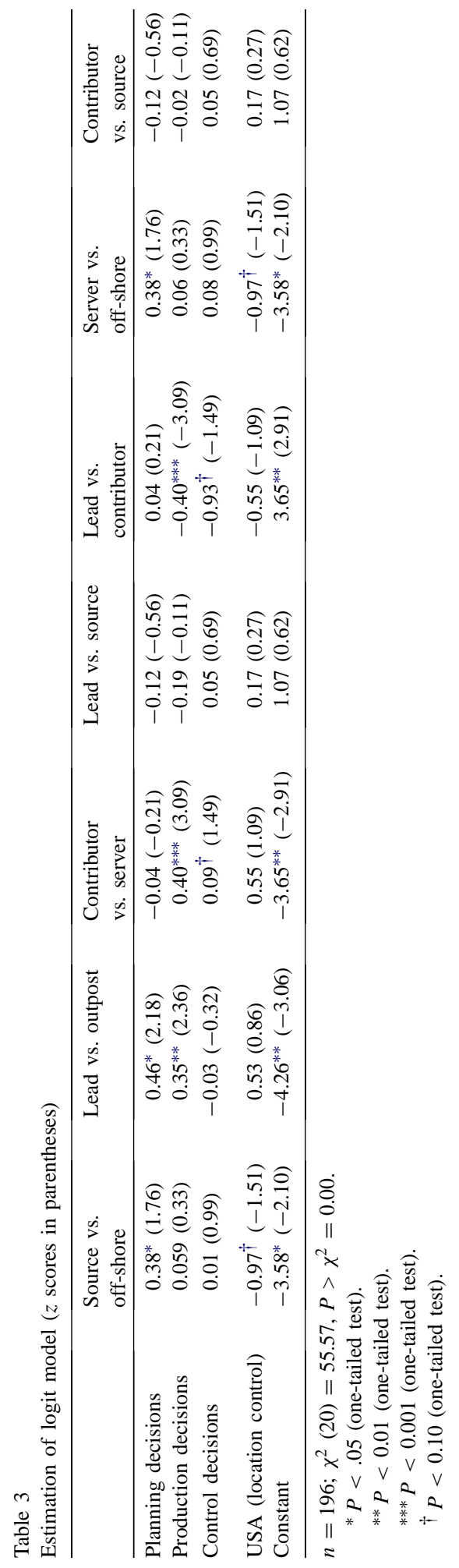


ogy at the site is fairly robust with respect to sign and significance. The significant technology-driven contrasts suggest greater autonomy over planning decisions for Source versus Off-Shore plants (H1a, $P<0.05$ ), for Lead versus Outpost plants (H1c, $P$ $<0.05$ ) but not for Contributor versus Server plants (H1b).

Because of its higher level of technological competence, we also expected that Lead plants would differ from Source and Contributor plants in their greater control over planning decisions. However, we find no support for $\mathrm{H} 2 \mathrm{a}$ and $\mathrm{H} 2 \mathrm{~b}$.

\subsection{Autonomy over production decisions}

There is no support for $\mathrm{H} 3 \mathrm{a}$ and $\mathrm{H} 3 \mathrm{~b}$ that there is greater autonomy over production decisions in Server versus Off-Shore, Contributor versus Source plants. There is also no support for $\mathrm{H} 3 \mathrm{c}$ and $\mathrm{H} 3 \mathrm{~d}$ that Lead plants would have greater autonomy over production decisions than Contributor and Source plants, respectively. Interestingly, there is a significant coefficient with the opposite sign indicating that Lead plants have less autonomy rather than more relative to Contributor plants concerning production decisions.

Equipment sourcing and component sourcing decisions may be shared with R\&D facilities for unique products made by Lead plants. This would tend to reduce their autonomy over these decisions. Further, some standard equipment sourcing and component sourcing may be delegated directly to Contributor and Source plants. This finding raises the possibility that the role of the Lead plant is quite different than the highly autonomous one that we hypothesized and we think Ferdows suggests.

\subsection{Autonomy over control decisions}

In support of $\mathrm{H} 4 \mathrm{~b}$, there is more autonomy for control decisions for Contributor versus Server plants $(P<0.10)$. However, there is no support for $\mathrm{H} 4 \mathrm{a}$ that Source plants would have more autonomy on control decisions than Off-Shore plants or $\mathrm{H} 4 \mathrm{c}$ that Lead plants would have more autonomy on control decisions than Outpost plants on control decisions. The little support for control de- cisions varying by degree of technical activities at the site could be because due to a desire for standardization, these decisions are retained and determined at headquarters or at the business unit level.

\subsection{Robustness tests}

To check the robustness of the results, we conducted several additional analyses. The classification of plants was based on a question that asked respondents the reasons for locating the plant. The original reason for locating an older plant may no longer hold and may not reflect the current role. Ferdows (1989, 1997) argues that plant roles may change over time. Respondents also answered a second question that asked about location criteria that would apply if the plant was to be located now. These "now" data reflect hypothetical choices and not actual ones but may capture additional information about current plant roles. We reclassified the 184 plants for which we had the "now" location data and found that 50 plants changed categories.

The logit model was re-estimated using the new classification of plants. The results for $\mathrm{H} 1, \mathrm{H} 2$ and $\mathrm{H} 4$, the Planning and Control hypotheses are unchanged. However, the results for some of the production hypotheses differ. While the $\mathrm{H} 3 \mathrm{~b}$ and $\mathrm{H} 3 \mathrm{c}$ remain unsupported, the results for $\mathrm{H} 3 \mathrm{a}$ and $\mathrm{H} 3 \mathrm{~d}$ change. In the original model, the Lead versus Contributor contrast was significant but negative, contrary to H3d. With the reclassification of plants, this significant but contrary result disappears. In the original model, the Server versus Off-Shore contrast was not significant as predicted by H3a. However, with the reclassification of plants, this contrast is significant $(P<0.10)$ but negative, indicating that Server plants have less autonomy over production decisions than do Off-Shore plants, contrary to the hypothesized direction. This contrary result may reflect the fact that Off-Shore plants are located for access to production inputs. The items comprising the Production decision factor are all related to sourcing; therefore, a plant located for access to inputs may control more of its sourcing decisions.

A second robustness check considered that Ferdows (1997) allows that a plant may have more than one role. Given the approach we take in our analysis, we 
could not accommodate a plant having multiple roles. When we classified the plants we restricted each to one role. However, when we assigned roles to plants, there were some plants that despite fitting best in one category based on our classification criteria could reasonably be placed into another category. We re-examined these "borderline" cases to investigate if our results are sensitive to the role that we assigned. There were 20 of our 196 plants that could arguably be reclassified based on the strategic reasons for the site and therefore conceivably have a second role. We assigned these plants to their alternative roles and re-estimated the logit model. The results for $\mathrm{H} 1, \mathrm{H} 2$ and $\mathrm{H} 4$, the Planning and Control hypotheses are unchanged. However, the results for some of the production hypotheses change with the reclassification. As we found with the reclassification based on the "now" location data discussed above, H3b remains unsupported, and the significant contrary result for H3d disappears. Also, as we found in the previous robustness test, the Server versus Off-Shore contrast is negative and significant $(P<0.05)$ contrary to H3a. In addition, the Lead versus Source contrast is significant but negative $(P<$ $0.10)$ contrary to H3c. Source plants, like Off-Shore plants, are located for access to inputs. Thus the argument made above, that plants located to access inputs, may have more autonomy for production decisions since they relate to sourcing - would also apply to this result.

Finally, we tested for industry effects. The multiindustry sample includes plants in 41 different 3-digit SIC codes. Two industries, pharmaceuticals and automotive are particularly well represented with 32 and 36 of the 196 plants, respectively, so we estimated a logit model with 0-1 control variables for the two industries. The inclusion of these industry controls did not change the results of the hypothesis tests.

\section{Discussion}

\subsection{Key results}

In this study, we applied the Ferdows $(1989,1997)$ framework that defines plant types and found it to be a useful device for organizing information about differences in autonomy over planning, production and control decisions among plants with different roles in multinational firms. The notion of differentiated fit is useful to help understand the operations and management of plants that are part of a network. Although this concept is typically applied to relationships between corporate headquarters and international subsidiaries in multinational firms and between corporate headquarters and business units in diversified firms, it is also applicable to the business unit-plant relationship. Different management systems fit different strategic plant roles.

We focused on one aspect of management systems, the autonomy the plant has over three types of decisions, planning, production and control, and tested whether this autonomy systematically differs among plants with different roles. Overall, the results are not strong. Our findings are strongest for the planning decision hypotheses. The control decision hypotheses are only weakly supported, a result that is consistent with the interpretation that the business unit and/or headquarters retains authority or centralizes these decisions for most plants. There is no support for the production decision hypotheses. However, an important result is that there are some contrary findings that raise interesting questions.

Although none of the production decision hypotheses were supported, we found that Lead plants had significantly less autonomy over production decisions than Contributor plants contrary to expectations. However, this finding is not as stable as the planning and control findings. In the robustness analysis conducted to investigate secondary roles of plants, this significant contrary result not only was no longer present but another significant contrary result emerged; Lead plants had significantly less autonomy over production decisions than Source plants. In both cases, Lead plants did not have the high level of autonomy that Ferdows suggests.

The insignificant and even contrary findings involving Lead plants suggest that the relationship between the role of a Lead plant and autonomy over managerial decisions may be more complex than the framework implies. We expected more autonomy over planning in Lead plants than in others, but it did not differ between Lead and other types of plants in the ways we expected. We attributed too much control over these decisions to Lead plants. The need for a Lead plant to coordinate activities across the network may mean it has less freedom in making independent decisions for 
its own operations. While this revised view contradicts the idea of the Lead plant as a plant with "absolute" control over important decisions, it acknowledges that there may be a positive interdependence with business unit headquarters or other plants. The significant contrary results in some of our tests indicating that Lead plants have less autonomy over production decisions than other plant types is also consistent with this explanation. Further research to investigate the constraints on a Lead plant's autonomy would be helpful.

\subsection{Limitations}

The study is based on a relatively small sample, particularly since we classify the plants into six types. Creating factors for categories of management decisions gave us sufficient degrees of freedom to estimate the logit model. The factors also simplified interpretation; however, grouping specific decisions into these categories might also have masked some differences within each category of decision type. Since we had a lack of significant results for many of our hypotheses it would be worthwhile, using a larger sample, to examine the individual decisions as discriminators to investigate whether particular constituent items were driving the result (or lack of result) for a factor.

Another limitation is that the sample we used is not random. Survey respondents were managers from firms with a demonstrated interest in multinational manufacturing issues. These firms may represent more leading edge management practices than firms in general. The results therefore should be interpreted as indications of practices of a sample of managerially sophisticated firms. Nonetheless, the analysis offers useful insights for plants in general.

A final limitation is that we have only investigated differentiation in management systems as defined by degree of autonomy over managerial decisions. There may be substantive differences in how plants with different roles are managed that would not be captured by their relative degrees of autonomy. However, finding some differences in autonomy that are consistent with our expectations is sufficient to argue that there is differentiated fit between management systems and plant roles.

\subsection{Implications}

Given that there is differentiated fit, if certain types of plants are combined in the same network differing levels of autonomy will be needed for some types of managerial decisions. For example, based on our results, one could combine Source and Off-Shore plants in the same network only if it is not too costly to differentiate planning decisions. Control decisions would have to be differentiated if Contributor and Server plants are combined. Other types of plants are more easily combined. For example, there are few systems which must be differentiated when combining Contributor and Source or Server and Off-Shore plants. If it is too costly to combine plants of different types, firms may choose to have predominantly one type of plant in its network and corresponding management systems matching that predominant type.

This issue of which types of plants to combine in plant networks raises the possibility that differentiated fit among plants within a business unit may also have implications for the headquarters-subsidiary relationship (Prahalad and Doz, 1987). While a strength of the Ferdows' framework is its detailed discussion of plant types and roles, a corresponding problem may be the absence of discussion of how these networks of plants might fit with particular firm organizations or business unit strategies. This absence may have led us to interpret Ferdows' framework as expecting higher autonomy on all dimensions for Lead plants. Certainly, the scope of the tasks assigned to Lead plants is the highest (Ferdows, 1989). But sometimes greater responsibility may correspond with less autonomy. For example, responsibility may require detailed cooperation with other plants, or other organizational entities, such as R\&D facilities of the business-unit headquarters, that are not explicitly part of the Ferdows' framework. Other frameworks, such as the idea of the Transnational firm of Bartlett and Ghoshal (1989) which explicitly talk about different types of multinational firm strategies may be usefully combined with plant networks described by Ferdows.

In this study we attempted to empirically validate some of the implications of Ferdows' framework for managing multinational plant networks and investigated whether different plants in the same company require different management systems. We focused on the autonomy that plants have over different types of 
management decisions and found evidence that management systems with respect to autonomy over key decisions are indeed different for plants with different strategic roles. Ferdows argues that understanding the strategic roles of plants in multinational networks helps companies exploit the plants' activities for the benefit of the network. The results of this study highlight the importance of understanding not only what strategic role each plant in a network plays but also how management systems might need to be differentiated so that the plants can pursue their roles effectively.

\section{Acknowledgements}

The research was conducted with financial support from the Technology Transfer Research Initiative at the Krannert School of Management. The data for this study are from a survey conducted by Brian Talbot and Aneel Karnani and we are grateful to them for the use of the survey results. We would also like to thank Anil Khurana, Clayton Hubner, and Joan Penner-Hahn who worked on the survey instrument and helped to create the database. Arnoud De Meyer gave us useful comments on an earlier draft.

\section{Appendix A. Profile of sample plants}

(A) Companies represented

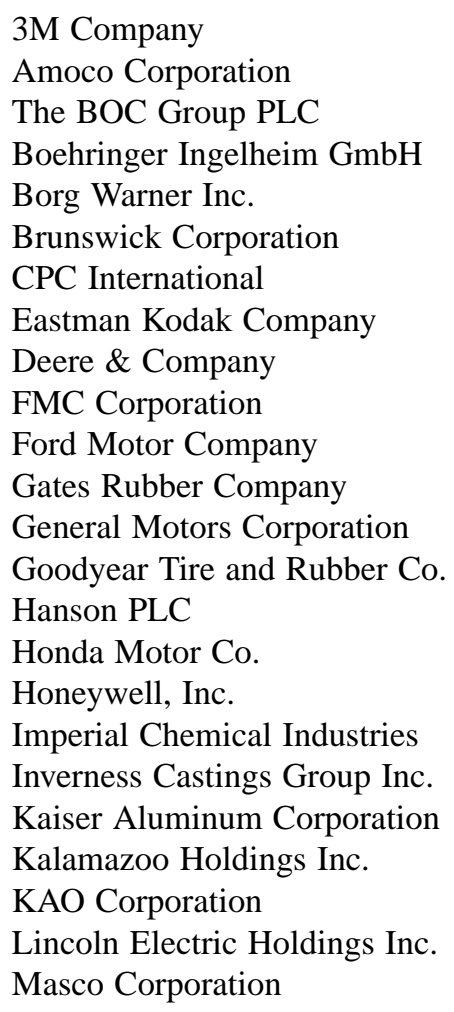

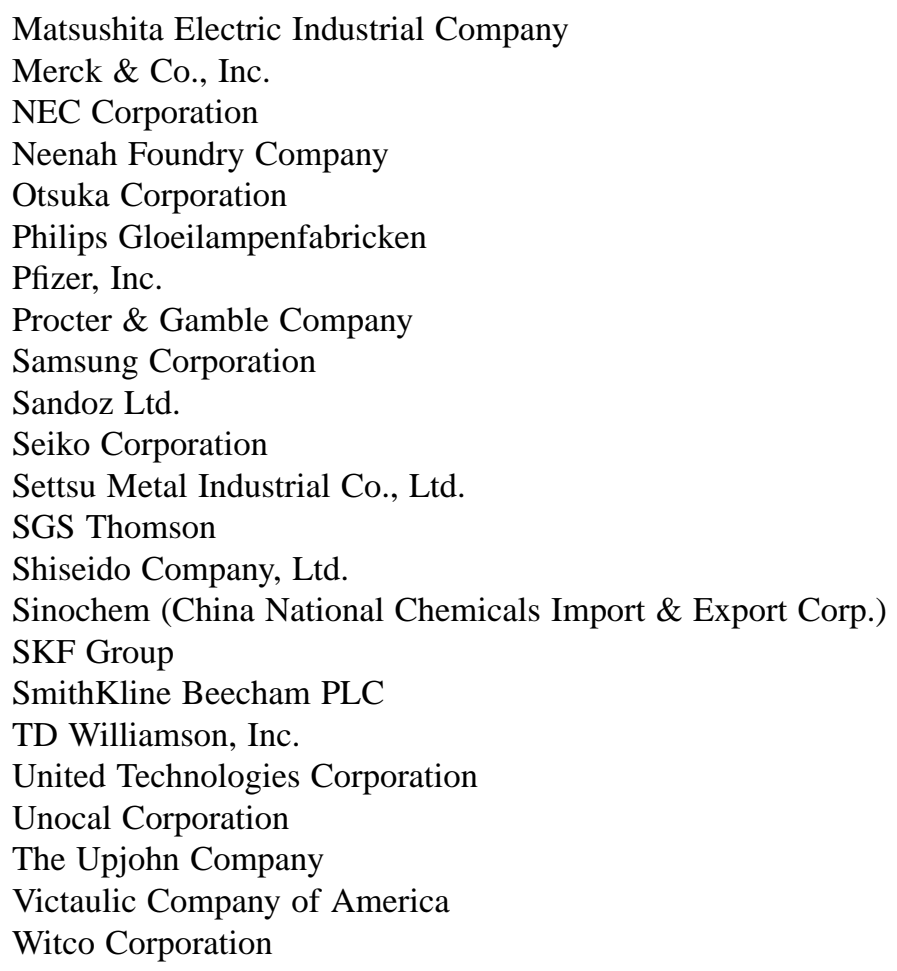


(B) Plant locations

\begin{tabular}{lllclc}
\hline Country & No. of plants & Country & No. of plants & Country & No. of plants \\
\hline Australia & 3 & India & 3 & Singapore & 3 \\
Austria & 1 & Indonesia & 4 & South Korea & 3 \\
Belgium & 1 & Ireland & 2 & Spain & 4 \\
Brazil & 3 & Italy & 2 & Sweden & 3 \\
Canada & 6 & Japan & 15 & Taiwan & 2 \\
China & 1 & Malaysia & 2 & Thailand & 2 \\
Egypt & 1 & Mexico & 3 & Turkey & 1 \\
France & 3 & Netherlands & 3 & United Kingdom & 16 \\
Germany & 9 & Nigeria & 1 & United States & 95 \\
Hong Kong & 1 & Philippines & 2 & Venezuela & 1 \\
\hline
\end{tabular}

(C) Plant SIC codes

\begin{tabular}{|c|c|c|c|}
\hline 3-Digit SIC for primary product & \multirow{2}{*}{$\begin{array}{c}\begin{array}{l}\text { No. of } \\
\text { plants }\end{array} \\
1\end{array}$} & 3-Digit SIC for primary product & \multirow{2}{*}{$\begin{array}{c}\begin{array}{l}\text { No. of } \\
\text { plants }\end{array} \\
2\end{array}$} \\
\hline 204 Food - grains & & 352 Industrial equipment - farm & \\
\hline 207 Food - fats and oils & 1 & $\begin{array}{l}354 \text { Industrial equipment - metalworking } \\
\text { machinery }\end{array}$ & 1 \\
\hline 209 Food - miscellaneous preparations & 1 & 355 Industrial equipment - specialty & 2 \\
\hline 208 Food - beverages & 1 & 356 Industrial equipment - general & 19 \\
\hline 267 Paper - products & 4 & 357 Industrial equipment - computers & 4 \\
\hline 276 Paper - business forms & 1 & $\begin{array}{l}358 \text { Industrial equipment - refrigeration and } \\
\text { service industry }\end{array}$ & 2 \\
\hline 281 Chemicals - industrial inorganic & 11 & 359 Industrial equipment - miscellaneous & 4 \\
\hline 283 Chemicals - pharmaceuticals & 32 & 361 Electronic and electrical - transmission & 2 \\
\hline 284 Chemicals - soaps and cosmetics & 19 & $\begin{array}{l}362 \text { Electronic and electrical - electrical and } \\
\text { industrial apparatus }\end{array}$ & 2 \\
\hline 286 Chemicals - industrial organic & 5 & 365 Electronic and electrical - audio and visual & 1 \\
\hline 287 Chemicals - agricultural & 1 & 367 Electronic and electrical - electronics & 5 \\
\hline 289 Chemicals - other & 4 & 371 Transporatation equipment - motor vehicle & 36 \\
\hline 291 Petroleum - refining & 2 & 372 Transporatation equipment - aircraft & 1 \\
\hline 301 Rubber - tires & 1 & 375 Transporatation equipment - motorcycles & 6 \\
\hline 305 Rubber - gaskets & 1 & $\begin{array}{l}382 \text { Measurement instruments - laboratory } \\
\text { equipment }\end{array}$ & 4 \\
\hline 321 Stone, glass, concrete - flat glass & 1 & 384 Measurement instruments - medical & 5 \\
\hline 332 Primary metals - iron and steel & 2 & 386 Measurement instruments - photographic & 1 \\
\hline 336 Primary metals - non-ferrous & 1 & 387 Measurement instruments - watches & 3 \\
\hline $\begin{array}{l}344 \text { Fabricated metal products - } \\
\text { structural }\end{array}$ & 1 & $\begin{array}{l}393 \text { Miscellaneous manufacturing - musical } \\
\text { instruments }\end{array}$ & 1 \\
\hline \multirow[t]{2}{*}{$348 \mathrm{~F}$} & 1 & 394 Miscellaneous manufacturing - games & 2 \\
\hline & & 399 Miscellaneous manufacturing - brushes & 1 \\
\hline
\end{tabular}




\section{References}

Bartlett, C., Ghoshal, S., 1989. Managing Across Borders: The Transnational Solution. Harvard Business School Press, Cambridge, MA.

Dean Jr., J.W., Snell, S.A., 1991. Integrated manufacturing and job design: moderating effects of organizational inertia. Academy of Management Journal 34 (4), 776-804.

Ferdows, K., 1989. Mapping international factory networks. In: Ferdows, K. (Ed.), Managing International Manufacturing. North-Holland, New York, pp. 3-21.

Ferdows, K., 1997. Making the most of foreign factories. In: Harvard Business Review, March-April, pp. 77-88.

Flaherty, T., 1986. Coordinating international manufacturing and technology. In: Michael Porter (Ed.), Competition in Global Industries. Harvard Business School Press, Boston, pp. 83109.

Gupta, A., Govindarajan, V., 1986. Resource sharing among SBU's: strategic antecedents and administrative implications. Academy of Management Journal 29 (4), 695-714.

Gupta, A., Govindarajan, V., 1991. Knowledge flows and the structure of control within multinational corporations. Academy of Management Review 16 (4), 768-792.

Khurana, A., Talbot, B., 1998. The internationalization process model through the lens of the global color picture tube industry. Journal of Operations Management 16 (2-3), 215-239.

Kotha, S., Vadlamani, B., 1995. Assessing generic strategies: an empirical examination of two competing typologies in discrete manufacturing industries. Strategic Management Journal 16 (1), 75-83.

MacCormack, A.D., Newman III, L.J., Rosenfeld, D.B., 1994. The new dynamics of global manufacturing site location. Sloan Management Review, Summer, pp. 69-80.
Miller, J.G., Roth, A.V., 1994. A taxonomy of manufacturing strategies. Management Science 40 (3), 285-304.

Nohria, N., Ghoshal, S., 1994. Differentiated fit and shared values: alternatives for managing headquarters-subsidiary relations. Strategic Management Journal 15, 491-502.

Oliff, M., Arpan, J., Dubois, F., 1989. Global manufacturing rationalization: the design and management of international factory networks. In: Ferdows, K. (Ed.), Managing International Manufacturing. North-Holland, New York, pp. 41-65.

Prahalad, C., Doz, Y., 1987. The Multinational Mission: Balancing Local Demands and Global Vision. The Free Press, New York.

Press, S.J., Wilson, S., 1978. Choosing between logistic regression and discriminant analysis. Journal of the American Statistical Association 73, 699-705.

Pugh, D.S., Hickson, D.J., Hinings, C.R., Turner, C., 1968. Dimensions of organization structure. Administrative Science Quarterly 13, 65-105.

Roth, A.V., Miller, J.G., 1992. Success factors in manufacturing. Business Horizons 35 (4), 73-81.

Scherer, F.M., Beckenstein, A., Kaufer, E., Murphy, R.D., 1975. The Economics of Multi-plant Operations. Harvard University Press, Cambridge, MA.

Schmenner, R., 1982. Multiplant manufacturing strategies among the fortune 500. Journal of Operations Management 2 (2), 7786.

Skinner, W., 1974. The focused factory. Harvard Business Review, May-June, pp. 113-121.

Swamidass, P., Newell, W., 1987. Manufacturing strategy, environmental uncertainty, and performance: a path analytic model. Management Science 33, 509-524.

Venkatraman, N., 1989. The concept of fit in strategy research: toward verbal and statistical correspondence. Academy of Management Review 14 (3), 423-444. 